\title{
La sociedad vasca y la conciencia de Nosotros
}

\section{Ander Gurrutxaga Abad \\ Alfonso Unceta}

Universidad del País Vasco

ander.gurrutxaga@ehu.es

\section{Resumen}

El artículo defiende la hipótesis de que la conciencia del Nosotros en el País Vasco depende, para su afirmación, de las instituciones y de los mecanismos que funcionan en el proceso de institucionalización de la vida inmediata. La definición de Nosotros en una sociedad plural, no es el producto de lo que separa a unos y a otros, sino de lo que los une. La unión se encuentra entre los procesos que componen la vida inmediata y las expectativas que se crean a través de ella.

Palabras clave: sociedad, vasca, conciencia, Nosotros, instituciones, vida cotidiana, identidad.

Abstract. The conscience of the basque society

The article defends the hypothesis that the conscience of the basque society dependsfor its affirmation on the institutions and the mechanisms that work in the process of institutionalization of the immediate life. The conscience of the community it is not the product of what separates people but of which it unites them in a plural society. This union is between the processes that compose the immediate life and the expectations that are created through it.

Key words: society, basque, conscience, institutions, identity.

\section{Sumario}

1. Introducción 4. La identidad del Nosotros:

2. Los cosidos sociales somos porque estamos de la sociedad vasca $\quad$ 5. Conclusiones

3. Referentes y significados en la sociedad vasca 


\section{Introducción}

El artículo se inspira en los resultados de una investigación que realizamos en el año $2003^{1}$. Las preguntas que la guiaron y las que trazan el recorrido de este artículo son las siguientes: ¿cómo se crea, se mantiene y se reproduce hoy la idea social de Nosotros? ¿Cuál es el significado de la conciencia de Nosotros en la sociedad vasca?

La hipótesis que desarrollamos es que la sociedad vasca es una sociedad plural, se encuentra con el hecho en el momento en el que se produce el proceso de institucionalización del curso de la vida. Algunos de los hitos de este proceso son: el origen geográfico de los individuos (nativos o inmigrantes), el territorio de residencia (Vizcaya, Álava o Guipúzcoa), la lengua cotidiana (euskera o castellano), las relaciones de vecindad, el barrio de residencia, la escuela o el colegio donde se educa a la prole, el lugar de trabajo, los espacios comunitarios que se comparten con los otros, las aspiraciones individuales y colectivas (sean éstas de índole económica, social, simbólica, etc.) y las definiciones del futuro.

Nuestra posición analítica tiene en cuenta estos datos porque creemos que no hay una sola interpretación sobre qué es la sociedad, sino que el pluralismo estructural caracteriza la percepción y la interpretación de la vida social, política, cultural y simbólica, de tal manera que estamos convencidos de que la idea de Nosotros no posee una fundamentación evidente, como tantas veces se sugiere desde la retórica pública y política. Al contrario, tal y como proponemos, la situación se describe mejor con el concepto de periferias sociales. Es así como la topografía vasca se asemeja a una red sobredeterminada por el curso de la vida, por las instituciones que la hacen posible y por el papel que tienen

1. El texto completo de la investigación está publicado en La producción de la idea del Nosotros: somos porque estamos (Vitoria-Gasteiz, Gobierno Vasco, 2005). En las páginas 9 y 10 del mismo decíamos que «la comprensión del problema sobre el que investigamos: la construcción de la conciencia del Nosotros en la sociedad vasca, descansa sobre la interdependencia entre el Yo y el Nosotros. Entendemos que ambos no pueden entenderse de manera separada si no es desde la comprensión depositada en la conciencia colectiva. Con esto lo que queremos indicar es que son la heterogeneidad de los principios culturales y sociales los que organizan la conducta pública. Los actores sociales adoptan muchos puntos de vista, como si la identidad no fuese sino el juego cambiante de identificaciones sucesivas, definidas de múltiples maneras, de tal forma que cuando los individuos construyen su idea de unidad lo hacen a partir de los diversos elementos de su vida social y de la multiplicidad de las orientaciones que portan [...] La metodología sigue los caminos que marca la dimensión discursiva, tratando de estudiar de qué manera son conformados los significados sociales de qué es hoy ser vasco. De esta manera, se pretende la articulación de las posiciones sociales desde las que se «habla" para producir, así, distintos discursos que den cuenta de la diversidad de las estrategias mediante las cuales se conforma el fenómeno en cuestión.

Partimos de considerar variables estructurales y estructurantes sobre el conocimiento o no de la lengua vasca — euskera-, la generación a lo que los sujetos intervinientes se adscriben, la estructura física del lugar de residencia y el género. Desde estos aprioris, hemos conformado ocho grupos de discusión compuestos por ocho personas cada uno. El material de estos grupos de discusión componen la base empírica fundamental de nuestro estudio». 
las instituciones comunes como lugares sociales desde donde se articulan los mínimos colectivos que aseguran la convivencia.

Sobre este telón de fondo, la política, por ejemplo, se designa como elemento de confrontación, a través del cual los contenidos y la definición de lo que es la sociedad son objeto de debate social y político. Y, entre las controversias habituales, nos topamos con el significado de la referencia estatal, el valor identitario atribuido por unos y por otros a la posesión de la lengua vasca - euskera- o las distintas posiciones ante el fenómeno de la violencia. Son algunos ejemplos de cuestiones que sesgan, en un sentido u otro, la interpretación de la realidad. Bajo estas condiciones, ¿cómo puede producirse la conciencia de Nosotros si no es utilizando aquello que une, aquello que cose la sociedad?

\section{Los cosidos sociales de la sociedad vasca}

Cuando reflexionamos sobre las transformaciones en la sociedad vasca, nos viene a la memoria el enigmático epígrafe de que vivimos sumidos en el tiempo final de las certidumbres. Tenemos la impresión que de «la noche a la mañana", sin tiempo para digerirlo, la sociedad vasca interioriza que, aunque desee proyectar la imagen de continuidad y coherencia con el pasado, éste está plagado de discontinuidades $y$, aún cuando evoque la idea de que tiene un centro ideológico inmutable y una periferia adaptada, de hecho, uno y otra están en permanente redefinición. Esto no se produce tan sólo porque los dilemas y las paradojas ocupen el espacio social, sino porque la sociedad que deseamos conocer asiste al presente atrapada por sus límites e incertidumbres.

Recientemente, se preguntaba el sociólogo alemán U. Beck ${ }^{2}$ : ¿̨en qué consiste el aglutinante social de las sociedades modernas? La respuesta sirve a este profesor de Munich para construir su cuadro de hipótesis tentativas. Tradicionalmente — decía Beck—, el primer aglutinante se alcanza a través de la religión; el segundo, por medio de «motivos de sangre»; el tercero, mediante el trabajo retribuido acompañado por las ideas de crecimiento económico, consumo masivo, y el cuarto, a través de la autointegración de los individuos.

La reflexión sobre el caso que nos ocupa, nos coloca en el último de los planos analíticos que Beck sugiere. ¿Por qué decimos esto? Porque en el mundo contemporáneo es habitual que las otras maneras de «atar», de "coser» las sociedades sean insuficientes, se agoten o fracasen, y su ausencia descubre algunas de las preguntas clave, como, por ejemplo: ¿qué mantiene unidas a sociedades individualizadas, privatizadas, secularizadas, es decir, a sociedades «sin religión» oficial, sin «sacrificios de sangre» y con la integración a través del trabajo, el bienestar y la educación puestas en entredicho?

Lo cierto es que, planteados de una u otra manera, algunos de los enigmas que atraviesan la definición del futuro pasan por contestar a nuevas preguntas

2. Ver el texto de BecK, U. Hijos de la Libertad. México: Fondo de Cultura Económica, 1999. 
que se derivan de la creciente debilidad de esos otros vínculos. Preguntas como éstas: ¿qué es lo que mantiene unidas a sociedades postreligiosas y postindustriales, más allá de las viejas imágenes de los adversarios, cuando no todo puede girar alrededor de ideas como las del trabajo seguro y retribuido o las de la nación como basamento de la integración? ¿Podrían quizá desempeñar ese papel la identidad, la cultura o la aceptación acrítica del multiculturalismo?

Ninguna de nuestras respuestas habituales tiene un cómodo asiento, a no ser que pretendamos obviar el necesario recorrido por el valor social del cambio y por las modificaciones habidas en el último siglo, que nos llevan hasta las transformaciones sociales, económicas y políticas que condicionan nuestro mundo en el siglo XXI y que tan poco se parece al que fuimos erigiendo a lo largo del siglo XX. Fruto de tales transformaciones debemos encarar hoy día fenómenos como el de la globalización, la reconfiguración del poder político, el multiculturalismo, el pluralismo radical, la individualización o la desinstitucionalización.

En el caso del que nos ocupamos — la sociedad vasca - para poder acercarnos a la respuesta, es preciso que tengamos en cuenta algunos hechos significativos. El primero tiene como referencia las transformaciones materiales que experimenta esta sociedad. Así, en los últimos veinticinco años, se representa el final de aquellos sectores industriales y productivos que hicieron posible la primera y la segunda revolución industrial, especialmente la siderurgia y el sector naval. Esto nos lleva a otro dato básico: la relación entre las mutaciones socioeconómicas y la metamorfosis en las referencias valorativas. Estos cambios ponen ante el espejo de la ciudadanía vasca un universo de problemas desconocidos hasta entrada la década de 1980; paro, migración de capital humano, recesión demográfica, incertidumbre laboral, desinterés por la cosa pública o cierta desafección por la política tradicional.

No es de extrañar que las transformaciones estructurales cuestionen la validez genérica de la cultura industrial que, como si de una argamasa se tratara, había cosido y cohesionado la sociedad industrial y la sociedad del trabajo. Si sabemos que la cultura es el juego de herramientas, de símbolos, relatos, rituales y visiones del mundo que la gente puede utilizar con diversas configuraciones para resolver los distintos tipos de problemas, la pregunta que surge con naturalidad es la siguiente: ¿qué o quién llena el espacio vacío que queda en los intersticios de las configuraciones sociales?

Desde las respuestas que se dan a esta pregunta, nace una segunda cuestión: ¿̇desde qué ideas y desde qué principios pueden construirse los mínimos comunes que articulan socialmente la sociedad vasca? La respuesta es que las certidumbres, cuando existen, deben proceder de la construcción del pluralismo de base porque, aún cuando haya definiciones e historias diferentes, compartimos experiencias comunes $y$, a veces, respuestas aceptadas genéricamente, $y$ con ellas elaboramos, si fuese necesario, los mínimos comunes que fundamentan la actividad de la ciudadanía.

Un hecho relevante, en el marco analítico que construimos, es la acción pública de las nuevas generaciones. Mantenemos la hipótesis de que las nuevas 
generaciones se afirman imbuidas de la idea del presentismo utilitarista y en confrontación difusa con la generación de sus mayores. No es éste un conflicto vivido dramáticamente, sino fundado en el respeto a la individualidad y a la comunitarización de las pautas de acción grupal. El valor de la tradición, transmitida por los adultos a los más jóvenes, no funciona y las referencias a doseles sagrados o a la política carecen, para ellos, de interés. Las nuevas generaciones están implicadas, aunque insuficientemente identificadas, con la defensa de espacios débiles de sentido, tenues, donde si algo se vislumbra es el ejercicio comunitario del encuentro grupal donde la búsqueda del otro se vehiculiza a través de la construcción de refugios privados, jsacralizados sí!, pero con la fría sacralidad del supermercado del sentido y bajo el prisma y la lógica del pragmatismo del consumidor satisfecho. Todo esto ocurre en paralelo a la redefinición de lo que es el compromiso con sus valores. Éstos se delinean en el plano de la relación intergrupal y en la búsqueda de la identificación pública, y no por medio de mecanismos tradicionales — militancia política, partidos, sindicatos, etc.- , sino por medio de mecanismos de participación en los fenómenos de la subpolítica —organizaciones no gubernamentales, movimientos medioambientales, objeción de conciencia, grupos por la paz, ayuda al Tercer Mundo, etc.

Hay otros hechos que, derivados de la acción política, impactan en la realidad vasca e inciden de manera significativa en la definición que analizamos en nuestra investigación. Nos referimos a los tres dilemas básicos que atraviesan esta realidad social. El primero es la posición nacionalismo versus no nacionalismo. La postura ante este dilema marca la dinámica sociopolítica vasca sin que se atisben en el horizonte elementos que indiquen que la separación entre unos — nacionalistas - y otros — no nacionalistas - vaya a superarse. Esta división es un elemento básico de identidad política, social y simbólica para todos los agentes implicados en el juego de lo social.

El segundo se refiere al proceso de institucionalización ${ }^{3}$ de la sociedad auto-

3. Las teorías que quieren comprender el sentido de las instituciones ponen el énfasis en el carácter central de éstas. Como afirma C. Offe (Las nuevas democracias, Madrid: Ed. Hacer, 2004 , p. 238), «las instituciones no son algo natural, sino algo producido por el hombre». Sin embargo, debido a su longevidad, parecen algo natural. Lo primero que asociamos a ellas es la estabilidad. Esto significa que la estabilidad se basa en un proceso social de reproducción idéntica regido por el efecto de socialización de las instituciones y por su viabilidad funcional. Las instituciones se protegen por la posibilidad que proporcionan a los actores de pasarse a otros códigos institucionales en caso de que su comportamiento no pueda ya acomodarse a las reglas de una institución. Lo que con esto queremos indicar es que el manejo de los entramados institucionales no depende sólo de su uso o habituación, siguiendo la estela que dejaron marcada P. Berger y T. Luckmann en La construcción social de la realidad (Buenos Aires: Ed. Amorrortu, 1968), los cuales, a su vez, recogían el legado que, desde la antropología filosófica, había depositado A. Gehlen en la perspectiva fenomenológica que tan bien supieron trasladar a los territorios de la sociología los dos autores citados. C. Castoriadis, en algunas de sus obras y, muy especialmente, en La institución imaginaria de la sociedad (Tusquets, 1983), ofrece una versión más inteligible para nuestros intereses analíticos, al expresar el carácter constituido constituyente de las instituciones y la exposición 
nómica vasca y plantea la configuración de un lenguaje específico, basado en la eficacia de la gestión y en las convenciones que promueven las reglas de juego institucionales aceptadas por la mayoría de los ciudadanos. La institucionalización y las instituciones comunes defienden y extienden un humus específico sobre el suelo de la sociedad vasca y cosen a ella el estatus específico de unos y de otros.

La tercera cuestión tiene que ver con los efectos que sobre el conjunto de la sociedad tiene el tema de la violencia. Es evidente - múltiples estudios empíricos así lo atestiguan - que hay una negativa rotunda por parte de la población a asumir esta forma de barbarie, pero también que los efectos de más de cuarenta años de presencia de ETA tienen incidencia directa en la socialización sociopolítica de tres generaciones de vascos.

Descifrar los enigmas que describen estos procesos no es tarea fácil ni cómo$\mathrm{da}$, incluso hay que interrogarse sobre si la ciencia social tiene instrumentos adecuados para abordar la magnitud de esta empresa. Da la impresión que la incertidumbre no es sólo el concepto que describe el tiempo presente, sino que es la percepción de la vivencia que penetra en las definiciones sociales, en las explicaciones de lo que es estar en sociedad y de lo que significa pertenecer a ella. Y, además, porque las respuestas que podamos encontrar en el mercado de la ciencia social se vinculan al estado de inestabilidad e inseguridad que caracteriza el comienzo del siglo XXI.

Supuesto lo anterior, no resulta fácil responder a la pregunta nuclear que está detrás del planteamiento de este artículo: ¿quiénes somos? Y ello es así, entre otras razones, porque de inmediato surge una nueva pregunta: ¿en qué sociedad vivimos?

Al tratar de responder a ambas cuestiones, nos encontramos con las reflexiones de F. Dubet ${ }^{4}$. Dice el sociólogo francés que la idea de sociedad concebida como una totalidad organizada funciona de la misma manera que la idea de comunidad del siglo pasado. La definición de sociedad como sistema natural o como conjunto de funciones ya no da cuenta de la complejidad ni de la diversidad de las conductas sociales. Los actores se ven obligados a gestionar racionalidades y lógicas diferentes.

de los individuos a crear, a producir y a reproducir instituciones como si éstas fueran instrumentos por y para el cambio. Sin querer abarcar aquí toda la tradición sociológica sobre tan sugerente tema, sí conviene traer a colación algunas obras, a nuestro modo de ver básicas y fundamentales, para sostener este carácter constituido constituyente que, según nuestra opinión, tienen las instituciones. Podríamos citar el ya clásico de Mary Douglas, ¿En qué piensan las instituciones? (Alianza, 1996) o los imprescindibles de R. Lourau, El análisis institucional (Amorrortu, 1970). Es también muy sugerente el texto de J. Elster, El cemento de la sociedad (Ed. Gedisa, 1991). No debemos olvidarnos tampoco de las obras de J. Meyer, J. Boli y G. Thomas, Institutional structure (Newbury Park: Sage Publications, 1982); T. Buns y E. Flam, The shaping of social organization (Londres: Sage Publication, 1982), y R. Bates, «Contre contractarianism: some reflections on the new institutionalism» (Politcs and Society, no 16, p. 382-401).

4. Dubet, F; Martuccell, D. ¿En qué sociedad vivimos? Buenos Aires: Losada, 1998. 
No obstante, no creemos que debamos conformarnos con esa aproximación. El replanteamiento no indica que se hayan resuelto las preguntas que formula la sociología clásica. Al contrario, muchas de ellas son y están de actualidad, en especial las que se interrogan por aquello que aglutina a cada sociedad. Algo sobre lo que también se pregunta F. Dubet ${ }^{5}$ : ¿cómo pensar la sociedad del siglo XXI y definirla como un conjunto relativamente homogéneo? ¿Acaso ésta puede ser fundada sobre la integración social misma, sobre la cultura, sobre otras referencias o sobre grandes valores interiorizados por los actores sociales?

Desde nuestra óptica, los dos fenómenos que tienen más capacidad explicativa son la desinstitucionalización y la individualización de los procesos de socialización. Lo que queremos indicar con esta afirmación es que ninguna de las grandes instituciones que tradicionalmente han cosido la sociedad y en cuyo interior los individuos se han socializado, en el bien entendido sentido de que tanto el yo como el nosotros forman parte de los objetivos básicos del proceso, pueden ser consideradas exclusivamente como instituciones, cuando menos en el sentido clásico del término, sean la escuela, la familia o las iglesias, por citar algunas de las más significadas. Éstas últimas son, en estos momentos, cuadros sociales, "perchas", con las que los individuos construyen sus experiencias, las cuelgan de esos cuadros y se forman como sujetos.

Sin embargo, a ninguno de los autores de cabecera ${ }^{6}$ de la tardía modernidad se le escapa el hecho de que si no podemos definir ya un tipo de sociedad construida sobre una lógica central, estamos obligados a tener que pensar y describir las sociedades en las que vivimos y, para ello, debemos huir de la fascinación por el vacío, al igual que no podemos caer en el mar de las tentaciones del nada cambia o del siempre nuevo. Lo que se vislumbra detrás de todo lo que sugerimos es que, como señala C. Geertz ${ }^{7}$, no sabemos cómo manejar un mundo que ni está dividido por sus gestores en las secciones que lo componen, ni es una unidad trascendente oscurecida por contrastes de temas y superficie que, en el mejor de los casos, son relegadas como distracciones inesenciales.

Lo más significativo de lo que estamos diciendo es que la idea clásica de sociedad — aquélla que creía en ella como unidad coherente-, da paso a formas nuevas en los albores del siglo XXI, de tal manera que una de las dificultades para encarar la vida social es que, a partir de esa ruptura, los actores sociales están obligados a forjar la representación de la sociedad que les permita otorgar sentido a nuevas situaciones vividas, en la mayor parte de los casos, con opacidad.

5. DubET, F. ¿En qué sociedad vivimos? op. cit.

6. Son muy interesantes, en este sentido, las obras de Z. Bauman, La sociedad individualizada (Madrid: Cátedra, 2001); La cultura como praxis (Barcelona: Paidós, 2002); La modernidad líquida (México: FCE, 2002), y La identidad (Madrid: Losada, 2005). De U. Beck, también hay que acercarse a leer: La individualización (Barcelona: Paidós, 2003), y La modernización reflexiva (Madrid: Alianza, 1997).

7. Geertz, C. Reflexiones antropológicas. Barcelona: Paidós, 2002. 
La conclusión es que si la sociedad de la modernidad está pensada como conjunto coherente y organizado por algunos elementos fundamentales, las respuestas de los análisis sociológicos dejan de lado la idea de totalidad y, por ende, la idea de sociedad regulada y autocentrada. El sueño durkheimiano se transforma en un dilema y cobra vigor en la expresión de que «en un mundo astillado debemos atender a las astillas».

Lo que estas formas de describir el presente detectan es que la imagen que se proyecta se asemeja a la realidad del magma en movimiento, donde todo está al alcance de la mano, pero donde no hay orden y lo nuevo y lo viejo pugnan entre sí, aunque ni el uno ni el otro se reconocen en sus denominaciones de origen. El ya citado F. Dubet ${ }^{8}$ explicita el problema cuando afirma que es el encuentro entre una estructura social compleja y movediza con una cultura cada vez menos institucionalizada lo que provoca el estallido de las identidades sociales.

Como indica Z. Bauman 9 , el «horror» de la nueva situación está en que el trabajo de construcción de la identidad puede resultar vano, porque el atractivo suele consistir en el hecho de mantener abiertas todas las posibilidades. No se trata de cómo descubrir, inventar, construir o comprar una identidad, sino de impedir que ésta se agarre demasiado al cuerpo y evitar que se fije de manera definitiva. Siendo las cosas así, lo que resulta relevante es la experiencia social, precisamente porque se basa en la heterogeneidad de los principios que organizan la conducta. Es decir, en la práctica, los actores están obligados a adoptar muchos puntos de vista, como si su identidad no fuese sino el juego de sucesivas identificaciones.

Parece como si la identidad pudiese ser definida de múltiples maneras y es que cuando los actores la construyen, lo hacen a partir de diversos elementos de su vida social y de la multiplicidad de relaciones que portan. Todo ello no es sino el resultado del dominio de la heterogeneidad sobre la experiencia social, algo muy característico de nuestro tiempo.

\section{Referentes y significados en la sociedad vasca}

Desde la perspectiva que hemos venido esbozando en el apartado anterior, la definición de lo que «se es» no incluye toda la actividad política y social de los ciudadanos. Asumir la circunstancia significa aceptar que los individuos comparten múltiples formas de identificación y que éstas son capaces de generar la cobertura y la seguridad suficientes ${ }^{10}$. Ello orilla, por lo general, las defini-

8. Ver el texto ya citado de F. Dubet y D. Martucelli, op. cit.

9. BAUMAN, Z. Identidad. Madrid: Losada, 2005.

10. No es el concepto de seguridad un lugar habitual en las disquisiciones sociológicas. Baste una rápida ojeada a los fondos bibliográficos para cerciorarse de que, mientras el término seguridad apenas figura, por el contrario, el término inseguridad se explicita mucho más. Véase, por ejemplo, la obra de N. Luhmann, La sociología del riesgo (Universidad de Guadalajara, 1992), cuando opta por la distinción entre riesgos y peligros en lugar de la de riesgo y 
ciones unívocas, dado que puede haber otros usos y algunas otras intensidades en el manejo de la definición de lo que es ser vasco.

Atendiendo a las razones anteriores, nuestra hipótesis es que los cosidos sociales en sociedades como la vasca no se basan tanto en la afirmación de aquellos rasgos que le son propios, como en la capacidad para atar los puntos básicos de la red que crea la interdependencia social en contextos de pluralismo radical. Esta característica no debe entenderse como un dato más, sino que es el dato estructural, básico y fundamental para comprender la estructura del presente. Una mirada a algunos datos empíricos puede ayudarnos a situar este hecho en sus justos límites. La tabla 1 nos permite describir un panorama significativo en estos términos, cuando analizamos cronológicamente la identidad nacional subjetiva.

seguridad, aduciendo que ésta última no es sino una ilusión social nunca alcanzable. La posición de U. Beck, La sociedad del riesgo (Paidós, 1998), tiene similares consecuencias. Es Z. Bauman quien, de manera más firme, se «atreve» con esta problemática, partiendo de la observación, que él atribuye a Beck aunque la podamos encontrar ya formulada en J. Habermas, de que ante la incertidumbre y las inseguridades de nuestro tiempo, todo nos impele a buscar soluciones biográficas a contradicciones sistémicas. La seguridad aparece identificada como lo propio, la cohesión comunitaria, las extensiones del endogrupo. No obstante, la tensión entre libertad y seguridad atraviesa toda la etapa de la modernidad líquida, como si ambos conceptos tuvieran una difícil convivencia, ya que, cuando se incrementa la libertad, desciende la seguridad y viceversa. Esta problemática recorre casi toda la trayectoria de Z. Bauman y la podemos encontrar en sus siguientes obras: Comunidad (Siglo XXI, 2003); La sociedad individualizada (Cátedra, 2001); Libertad (Alianza, 1991); Modernidad y holocausto (Sequitur, 1997); La globalización: sus consecuencias humanas (FCE, 2002); Modernidad y ambivalencia (Anthropos, 2005); En Busca de la política (FCE, 2002); Modernidadl líquida (FCE, 2003), y La sociedad sitiada (FCE, 2004). Son muy sugerentes las llamadas a la ironía sociológica en las aportaciones de N. Luhmann a este debate. Dice que el riesgo reclamado por la sociología, «es una nueva oportunidad para completar con un nuevo contenido su viejo rol, el de alarmar a la sociedad». N. Luhmann construye un concepto constructivo y relacional que sostiene un triple eje: riesgo, peligro y seguridad. El problema del planteamiento de este autor es que, así como desarrolla los dos primeros conceptos, el tercrero — seguridad- lo da por supuesto. En su ya citada Sociología del riesgo, acomete esta empresa y la deriva hacia otro problema: la aceptabilidad del riesgo y la gestión del mismo. A. Giddens aborda el problema de la seguridad desde la preocupación por el riesgo en sus obras: La transformación de la intimidad (Cátedra, 1998); Consecuencias de la modernidad (Alianza, 1999); Un mundo desbocado (Taurus, 2000); Modernidad e identidad del yo (Península, 1995), y La constitución de la sociedad (Amorrortu, 1995). La opción de Giddens pone en relación los contextos de la modernidad tardía con los contextos de riesgos nacidos del éxito de la misma modernidad. En este sentido, lo que se gestiona es el éxito de modernidad y las consecuencias de éste. Lo que ocurre es que, en estas condiciones, pensar en términos de riesgos y de su evaluación es una práctica más o menos generalizada de características en parte imponderables, tanto para loa agentes como para los expertos específicos. El clima de riesgo de la modernidad es perturbador para cualquiera, nadie puede evitarlo y ello explica la evacuación del concepto (restringido) de seguridad. La conclusión de unos y otros planteamientos es que la seguridad aparece como una necesidad derivada de los riesgos que provoca la misma modernidad, lo que ocurre es que el riesgo se generaliza y también la necesidad de seguridad. Lo que ocurre que ésta es precaria, mira tanto en los rincones de lo cotidiano como en la seguridad estructural u ontológica que puede ofrecer nuestra sociedad. 
Tabla 1. Evolución de la identidad nacional subjetiva.

19871988198919901991199219931994199519961997199819992000200120022003

$\begin{array}{llllllllllllllllll}\begin{array}{c}\text { Preferentemente } \\ \text { vasco/a }\end{array} & 46 & 48 & 46 & 47 & 48 & 47 & 46 & 44 & 46 & 44 & 49 & 47 & 46 & 47 & 42 & 47 & 47\end{array}$

\begin{tabular}{lccccccccccccccccc}
\hline $\begin{array}{l}\text { Tan vasco/a } \\
\text { como español/a }\end{array}$ & 35 & 31 & 31 & 32 & 34 & 34 & 33 & 36 & 36 & 37 & 32 & 34 & 35 & 38 & 38 & 36 & 36 \\
\hline $\begin{array}{l}\text { Preferentemente } \\
\text { español/a }\end{array}$ & 18 & 18 & 20 & 18 & 16 & 15 & 17 & 16 & 15 & 15 & 13 & 16 & 13 & 12 & 15 & 14 & 10 \\
\hline $\begin{array}{l}\text { No sabe / } \\
\text { no contesta }\end{array}$ & 2 & 3 & 3 & 3 & 3 & 3 & 4 & 4 & 4 & 4 & 7 & 8 & 7 & 5 & 7 & 7 & 7 \\
\hline
\end{tabular}

Fuente: seguimiento de la situación sociopolítica del País Vasco 1987-1995 y Sociómetro Vasco 1995-2003. Elaboración propia.

En el caso de la sociedad vasca, el encuentro con el pluralismo se realiza en el marco que definen los ámbitos donde se institucionaliza el curso de la vida. Y es en ellos donde toma cuerpo el juego de la interdependencia, lo cual da lugar a muchos modos de vida en los que los individuos pueden desarrollarse. Esta evidencia lleva a una conclusión: no necesitamos valores comunes para vivir juntos y en paz, sino que necesitamos instituciones comunes en las que muchas formas de vida pueden coexistir.

Apoyándonos en estas premisas, nuestro discurso analítico se sostiene sobre la idea de que la definición que la sociedad vasca hace de la idea de Nosotros está relacionada con los hitos significativos que institucionalizan el curso de la vida, con la institucionalización de la idea de lo que signifique la seguridad y con los contenidos que representan la idea de futuro.

Lo que queremos enfatizar es que no hay, en estas definiciones, esencias inmutables, sino procesos de construcción de las definiciones sociales. No existe, a nuestro entender, un núcleo suficientemente articulado, atemporal, definitivo, esencial, que pueda denominarse «cultura», sino procesos abiertos al futuro, procesos que erigen creencias, valores, normas, etc. Es este carácter permanentemente abierto e inacabado el propio del tiempo del presente y, en ocasiones, el que da pie a la confusión de los contenidos y al desenlace híbrido, a la «contaminación» de aquello que parece obvio, fijo e inalterable.

De hecho, lo que demuestra la experiencia social es que son las adscripciones diversas, las identificaciones sucesivas y las lealtades múltiples, tanto en sus relaciones con los contenidos como con los soportes, los rasgos básicos con los que hoy trabaja la cultura. Lo que significa, expresado de otra manera, ser conscientes de que habitamos escenarios abiertos, híbridos, donde lo único sólido es la frontera ${ }^{11}$.

11. La noción de frontera y de nosotros está muy bien desarrollada en la obra de F. Barth, Los grupos étnicos y sus fronteras (México: FCE, 1974). Ciertamente, la antropología de F. Barth no está sola en el desarrollo de este concepto, aunque bien es verdad que él y su escuela 
La frontera es el territorio donde se vive o por elección o por necesidad. A ella le acompañan la confusión, la incertidumbre, la ambivalencia y la ambigüedad. No es un espacio social claro o fácil, sino difícil y complejo, un escenario de sobreofertas identitarias, de sobreoferta de valores, de supermercado del sentido. Es un escenario social y simbólico de intenso intercambio social, es el terreno abonado tanto para el entendimiento como para el enfrentamiento entre mosaicos de culturas y con los sentimientos tribales que abundan y que, con ella y en ella, se expresan.

No es baladí, en absoluto, preguntarse qué tendencia se impondrá. Lo que ocurre es que esta pregunta no tiene una respuesta concluyente. La "cultura vasca de frontera" lo que exhibe es el pluralismo cultural, no un tiempo de desesperación, nihilismo o el punto final de la racionalidad humana. Con esto queremos decir que la conciencia de pertenecer a algo, de identificarse con signos, con símbolos, con valores, no pasa de ser un guión de lo que es la pertenencia. Un guión que se lee, que se confronta y que se utiliza para alcanzar unos $\mathrm{u}$ otros fines, que no se entiende como un hecho inmutable en la vida. Se crea a partir de realidades sociales, cambia con ellas y siempre incluye puntos de vista acerca de Nosotros y de los Otros.

Las descripciones que estamos manejando hay que complementarlas con algunos aspectos básicos que sobresalen en nuestra investigación. Siguiendo con lo citado, es obvio que la definición de una forma de estar en la sociedad pasa por la imagen que los individuos se construyen de lo que esa sociedad es.

En nuestro caso, hay una nítida percepción de que, como se cita literalmente en los diversos grupos de discusión, «aquí se vive bien». El buen vivir está asociado a lo que es la calidad de vida y a un sentido, más o menos difuso, de lo que es la seguridad que proporciona la vida inmediata. Esta respuesta está generalizada entre nuestros entrevistados. No obstante, no es una definición estática, algo que "ya está», sino que nace asociada a múltiples expectativas. Da la impresión que éstas componen el universo de seguridad y de certidumbre que los individuos necesitan para afirmarse como pertenecientes al Nosotros. «Bien vivir» significa calidad de vida y ésta está asociada

abren un escenario novedoso para la ciencia social. Desde otras perspectivas, son muy sugerentes otras obras como la de Z. Bauman, La cultura como praxis (Paidos, 1999), ya que desarrolla un concepto abierto, alejado de cualquier pretensión esencialista de qué es la cultura y los aditamentos sobre la que se soporta. El mismo autor maneja estos conceptos en sus ya citadas obras Comunidad o La modernidad líquida. La obra que compilan S. Hall y Paul du Gay, Cuestiones de identidad cultural (Amorrortu, 2003) es muy sugerente. Hay que regresar a autores como Garcia Canclini, sobre todo en Culturas híbridas (Paidós, 2001); La globalización imaginada (Paidós, 1999), y Diferentes, desiguales y desconectados (Gedisa, 2005). La obra de H. K. Bhabha, El lugar de la cultura (Manantial, 2002) es muy sugerente. Las aplicaciones de estos conceptos en autores como A. Appadurai, La modernidad desbordada (FCE, 2001), y S. Lash, Economías de signos y espacios (Amorrortu, 1998), son muy sugerentes. He tenido oportunidad de desarrollar más estos conceptos en mis obras: Ander Gurrutxaga, El código nacionalista vasco en el franquismo (Antrophos, 1986), y La Mirada difusa (Alberdania, 2002). 
a las oportunidades que ofrece la sociedad vasca, pero también a las expectativas que los ciudadanos han construido con su quehacer social en los espacios de encuentro interpersonal.

Hay un hecho digno de ser destacado y es que, prácticamente en todos los participantes en los grupos de discusión, hemos comprobado que no hay definiciones fuertes ni excluyentes de lo que es ser vasco. Al contrario, las expectativas se asocian al funcionamiento normalizado de las instituciones de la vida inmediata, al hecho de disfrutar de aquello que se tiene y a poder adivinar un futuro para la prole. La conclusión de la posición es que los entrevistados dejan claro que la economía política de la seguridad pasa por el recurso al trabajo como la forma más adecuada de poder mantener las expectativas vitales y de construirse un futuro, por el bienestar de la prole - la familia-y por que las expectativas que unos y otros hacen puedan cumplirse.

Si se consigue lo que nuestros entrevistados indican, la definición de «quienes somos nosotros» no depende de discursos concluyentes, sino de definiciones seguras y de expectativas viables, no de entelequias esenciales o de identidades que obligan a pronunciarse en términos excluyentes. Es algo débil, envolvente, o quizá, para ser más preciso, habría que decir que la fortaleza está precisamente en su aparente debilidad.

Las expectativas ciudadanas se erigen sobre una definición y sobre una presunción: la seguridad que otorga el vocablo social «estamos», pero también sobre los hechos cumplidos y sobre las expectativas. De esta manera, éstas no necesitan de discursos explícitos, sino de que su legitimación esté soportada sobre instituciones que vehiculizan el sentido de seguridad. Los ciudadanos lo que hacen es confrontarse con ellas y perciben que éstas pueden cumplirse a través de los entramados institucionales que atan y cosen la realidad de lo cotidiano, de lo inmediato, de lo más cercano.

Lo importante, para el caso que nos ocupa, es que las expectativas forjadas puedan cumplirse, por ejemplo: la esperanza de futuro que se identifica con el bienestar propio y con el de la prole, y que se quieren alcanzar a través de los mecanismos institucionales previstos: trabajo y educación, sobre todo. Esta argumentación se reproduce, con más o menos insistencia, en todos los entrevistados. Las respuestas guardan estrecha relación con la centralidad que adquiere la seguridad que otorgan la definición colectiva "estamos» y las expectativas cumplidas. Las expectativas no requieren de discursos explícitos, sino que su legitimación está soportada sobre las instituciones que vehiculizan el sentido de seguridad. Los ciudadanos se confrontan con ellas y perciben que éstas se cumplen o que pueden cumplirse a través de los entramados institucionales que atan y cosen el mosaico de la realidad de lo cotidiano.

Las instituciones que componen la economía política de la seguridad son el abigarrado puzzle al que cosen los entrevistados sus respuestas ante el dilema de qué es formar parte de la sociedad vasca y de cómo situarse ante ella. Sorpresivamente, casi no se recurre a la ommipresente política —algo que en muchos discursos públicos y de los medios de comunicación es cuestión cuasi obsesiva - cuando se cita a la sociedad vasca, ni se echa de menos el legado de 
la tradición o cualesquiera otros recursos ajenos al vivir cotidiano, ocurre que todo lo que dicen que tiene valor debe ser visado por el sentido de aquello que se percibe cercano e inmediato para la lógica del «estamos», pero "estamos» quiere decir que es el entramado institucional inmediato el llamado a cumplir con esas funciones y con esas expectativas. Por eso, unas expectativas y otras se cumplen si la institucionalización de los recursos que promueve la vida cotidiana funcionan y otorgan los bienes y el bienestar que se persigue.

Siendo así, el dilema de la cohesión o las llamadas al interrogante sobre ¿quiénes somos Nosotros? desvela que la respuesta no depende de llamadas a vínculos o a relaciones imposibles, sino de la circularidad y de la reproducción ampliada de las expectativas que se encuentran con el poder de institucionalizarse mediante las actividades de la vida inmediata. De aquí, el valor que adquiere este núcleo de lo inmediato — sean la familia, el vecindario, los amigos, etc.

Es como si el principio de confianza en sí mismo encontrara las expectativas más adecuadas en el juego de las instituciones de la vida inmediata y en la adscripción al juego institucional, porque, en el fondo, están convencidos de que, fuera de esos marcos, la recompensa es imposible. La confianza en el «estamos» que promueve este juego institucional no necesita de discursos explícitos para afirmarse como argamasa genérica. Está ahí, a su disposición, y ésta es su virtud. Por el contrario, "huyen» de definiciones explícitas frente a aquellas realidades que les suenan problemáticas, especialmente la realidad de la política y, en menor grado, la lengua - el euskera.

Bien es verdad que los marcos que definen la seguridad varían para las diversas generaciones. Entre la generación joven, la seguridad equivale al cumplimiento de las expectativas que les señala su idea de futuro: confían en la familia, confían en los estudios, confían en los amigos. Es el momento de esperar todo de lo que les rodea.

Para las generaciones intermedias, se acerca ese momento donde descubrir que fuera del juego de las instituciones «no hay nada». Las generaciones adultas se han asentado, por el contrario, alrededor de su posición biográfica realizada o realizable a través de los canales institucionales previstos. En este marco es donde todos creen encontrar el punto mínimo donde encontrarse con el otro y con los otros.

\section{La identidad del Nosotros: somos porque estamos}

Sabiendo lo anterior, y conociendo que es frecuente entre los estudios que se han ocupado de la sociedad vasca, encontrar la explicación de sus peculiaridades en variables sociosimbólicas y políticas, y que tales variables son contextos estructurales de explicación, en nuestro caso, tal y como hemos explicitado en el apartado anterior, creemos detectar, a partir del análisis cualitativo y cuantitativo que hemos llevado a cabo, que son las instituciones que institucionalizan el curso de la vida los ejes clave que explican hoy la producción de la idea de Nosotros. 
Siendo así las cosas, el diseño gráfico de la arquitectura social vasca representa a las instituciones del curso vital y a las instituciones comunes sosteniendo una red de periferias en permanente debate entre ellas mismas, alrededor de los hitos anteriormente mencionados.

El razonamiento que sostiene esta afirmación es el siguiente: si la tradición no tiene una sola interpretación; si el pluralismo marca los diversos aspectos de la vida social, política, cultural y simbólica; si la cultura es un elemento divisivo; si la política se designa como un elemento de confrontación; si los contenidos y las definiciones de lo que sea la nación son objeto de debate social permanente; si las referencias a los estadonacionales son cosas distintas para unos y para otros; si la lengua vasca marca un eje identitario, y si la violencia sesga las interpretaciones de la realidad, ¿cómo puede producirse la conciencia de Nosotros si no es utilizando aquello que ata, aquello que cose, es decir, las instituciones del curso vital y las instituciones comunes?

Detrás del cuadro que acabamos de dibujar, se erige la importancia del vivir, la institucionalización de lo social a través de la vida cotidiana. No es extraño que las instituciones comunes, aquéllas que se comparten y que son reconocidas por la mayoría de la población, sean las que articulen la singularidad de aquello que definimos como Nosotros. Es cierto que la definición del concepto está atravesada por variables independientes como la edad, el origen geográfico de los ciudadanos, el territorio de residencia, la lengua materna y de uso cotidiano, el voto electoral de preferencia o la identificación con una o varias identidades de entre las existentes en el mercado social de la sociedad vasca.

Ahora bien, lo que los datos empíricos ${ }^{12}$ y censales señalan es que los ciudadanos del País Vasco, si bien matizan algunas de las lecturas de la realidad o toman postura ante las ofertas sociales y políticas, lo que comparten es el espacio social, simbólicamente construido. Es en este espacio donde las fronteras sociales, si bien construyen y definen los límites, no aparecen como fronteras que excluyan en su mirada hacia adentro, sino fronteras que permiten mantener la definición social de «somos porque estamos». Detrás de esta evidencia, se esconde la problemática de la articulación de las sociedades complejas y plurales y el debate sobre su definición. En el caso de la sociedad vasca, es el debate sobre las ideas y sobre los principios que pueden, a modo de cosidos, constituirse en mínimos comunes.

Lo que el análisis de los grupos de discusión muestran es que la conciencia de Nosotros está asociada a la idea de «somos porque estamos», lo cual

12. Véanse los análisis del Sociómetro Vasco, del Euskobarómetro y del Centro de Investigaciones Sociológicas. Si hacemos un seguimiento desde marzo de 1996 hasta la actualidad de los resultados que recogen unos y otros, nos encontramos con esta realidad; estar significa 'compartir', lo cual nos conduce a percibir el sentido empírico de las diferencias que sostienen el pluralismo. Véanse, a modo de ejemplo, los estudios 1513, 1757, 2096, 2296 y 2407 del CIS, correspondientes a 1986, 1988, 1994, 1998 y 2001, o los análisis del Gabinete de Prospección Sociológica, titulados Sociómetro Vasco, no 1, 2, 3, 4, 5, 6, 7, 8, 9, 10, 11, 12, $13,14,15,16,17,18,19,20,21$, correspondientes a los años 1996/2003. 
quiere decir que las definiciones sociales dependen de expectativas y están, en consecuencia, abiertas a múltiples influencias y a una oferta de propuestas y de soluciones entre las que cabe optar. Por eso, los ciudadanos de la sociedad vasca delatan actitudes de consumidor, eligen entre la variedad de ofertas que encuentran en el mercado del sentido y clasifican estas ofertas dependiendo de la definición social que han hecho de ellas y de la importancia concedida a unas y a otras. Nada se pasa por alto, unas y otras se encuentran ante los individuos que las clasifican, las dan un sentido y construyen la identidad con ellas.

La consecuencia más importante es que la institucionalización de lo que representa la vida inmediata aparece como el universo que integra los mínimos comunes con los que la sociedad vasca crea y busca la cohesión. Son, de esta manera, los vínculos sociales de la socialidad inmediata los que generan la definición fuerte de la vivencia de la identidad en la sociedad vasca. No ocurre lo mismo con aquellos signos que, siendo significativos, lo son específicamente para determinadas realidades, tanto si se trata, por ejemplo, de la lengua - el euskera-, como de la política.

De ahí que, en la sociedad vasca, las definiciones exclusivas o excluyentes sobre la pregunta "¿Quiénes somos?», cuando existen, no tienen la capacidad para articular la amalgama social. Lo que no existe es el centro que articule esa conciencia, sino que la diversidad de identidades es la consecuencia del pluralismo, es éste el que se impone como matriz simbólica y referente estructural en los territorios de la diversidad vasca. «Somos porque estamos» diseña un cuadro factible de respuestas a los interrogantes y dilemas que hemos presentado a lo largo de este artículo. Es la seguridad que otorga esta definición la que mantiene y reproduce la argamasa genérica de la cohesión social.

Esta definición se canaliza a través de las expectativas que provocan las instituciones que atan y cosen el mosaico social. Los cosidos dependen de que las expectativas forjadas se cumplan. Sean el bienestar personal o de la familia, la estrategia elaborada para la prole, el trabajo, la educación, etc. Todas se presentan como instituciones activas que crean expectativas. Lo que demuestra es que el dilema de la cohesión no depende de llamadas extemporáneas a vínculos imposibles, sino de la circularidad de las expectativas que se institucionalizan.

La conciencia de Nosotros que estamos describiendo gesta una concepción de seguridad. En la sociedad vasca, la idea compartida de seguridad se muestra a través de la experiencia colectiva de que «somos porque estamos». Es en esta representación de la concepción sociopolítica que tiene de sí misma la sociedad vasca donde se concita tanto lo sincrónico (ser/estar) como lo diacrónico (el devenir, el llegar a ser/estar) y, asimismo, se hace reconocible el proceso de conformación de un marco común de seguridad. Es el marco en el que las instituciones recrean expectativas, las generan y las renuevan. Son éstas las que, institucionalizadas, se constituyen a la vez en horizonte de sentido de dichas instituciones, mostrándose así no sólo como meros productos, sino también como productores de éstas. 
En este sentido, la imagen de que «somos porque estamos» supone la reproducción narrativa de la serie de expectativas institucionalizadas que constituyen el Nosotros. De ahí que, al tomar en consideración esta imagen, no hagamos otra cosa sino plantear la seguridad en los términos de un imaginario colectivo o, si se prefiere, en el conjunto de formas específicas y modos legítimos de "hacer visible» una sociedad en una época concreta. De hecho, la imagen de que «somos porque estamos» no sólo nos deja ver la idea común de seguridad en la sociedad vasca de comienzos del siglo XXI, sino que, además, nos la hace ver de una determinada manera, la que incorpora tanto lo que supone mantener o atenerse a lo que nos une y ata («somos») como atender a lo que comporta su significación («porque estamos»).

\section{Conclusiones}

A lo largo de nuestra investigación, nos hemos encontrado con una situación de perplejidad, definida en gran medida por el alto grado de pluralismo de la sociedad vasca. Éste es un dato estructural y un hito básico de «nuestro» problema. Así, la creación de la conciencia del Nosotros se enmarca en la situación donde se encuentra una estructura social cada vez más compleja y movediza con una cultura que cada vez institucionaliza menos y que obliga a replantear la situación del Nosotros en la situación del presente.

La identidad que sostiene la conciencia del Nosotros se abre a un permanente proceso de construcción que llevan a cabo individuos particulares que se expresan como tales mediante la transformación de los mínimos comunes en referentes ineludibles. Estos encuentran su lugar «natural» en los mecanismos básicos que sostienen la vida inmediata, la vida cotidiana.

La construcción de la conciencia del Nosotros impulsa a sus creadores a buscar perchas en las que colgar junto a otros la incertidumbre que rige nuestras vidas. Si las comunidades de esa naturaleza consiguen o no sus objetivos es otra cuestión, pero encontrarse con los otros, aunque sea en los espacios inmediatos de la vida cotidiana, sí proporciona alivio y seguridad.

La definición de lo social designa las conductas individuales y colectivas que están dominadas por la heterogeneidad de los principios constitutivos y por la actividad de los individuos que deben encontrar el sentido a lo que hacen dentro del mundo heterogéneo que describe la realidad de lo social. Es precisamente esta realidad la que describe la heterogeneidad de los principios culturales y sociales que se acogen bajo el paraguas del pluralismo, los que organizan la conducta social. Lo que nuestros investigados concluyen es que ellos son actores de una realidad que los envuelve pero que les obliga a adoptar, simultáneamente, muchos puntos de vista, como si su posición no fuera más que el juego cambiante de identificaciones sucesivas o como si su realidad fuera transformada no por realidades ajenas a la vida de lo inmediato, sino por instituciones que están al alcance de lo inmediato, en la vida ordinaria de los sujetos.

Detrás de esta fórmula aparece, con radicalidad, la problemática de la articulación de las sociedades complejas y plurales y de cómo quieren éstas defi- 
nirse a sí mismas. La pregunta surge inmediatamente: ¿Desde qué ideas y desde qué principios pueden construirse los mínimos comunes que cosen socialmente a la sociedad vasca? Ahora bien, contestar acertadamente a estas dos preguntas supone tener presentes algunos hechos: el primero es que no hemos encontrado esencias inmutables, sino procesos de construcción, de cambio y de transformación. Con esto queremos indicar que no hay, en la sociedad vasca, nada parecido a una economía política de las esencias, sino todo lo contrario, no hay un núcleo suficientemente articulado, atemporal o definitivo que pueda denominarse "cultura", sino procesos abiertos al futuro, procesos sobre los que se erigen creencias, valores, normas, etc. Todos ellos están sometidos a lecturas de su significado, a desafíos sobre lo que puede ser y sobre lo que nunca termina de ser. Luego esta apertura, su carácter inacabado, es lo que describe mejor el momento en el que la construcción de la conciencia del Nosotros adquiere su significado. Pero, a su vez, esto significa que la realidad desde la que los individuos se mueven, la realidad que manejan todos los días, es una realidad múltiple, una realidad por la cual tienen que transitar, que los envuelve y que obliga a unos y a otros a definirse en los términos definidos por la multiplicidad de preguntas y de respuestas que salen a su paso. Por eso, la mirada que hemos propuesto descansa sobre cuatro momentos; distinguimos el tiempo histórico, el tiempo social, el tiempo político y el tiempo reflexivo.

Cada uno de estos tiempos tiene un tratamiento específico y una forma de acercarse a este fenómeno. Todos ellos, a su vez, se presentan entremezclados, de tal manera que la lógica política, la historia y la percepción social del proceso se mantienen desde la interdependencia de las partes. De esta manera es como hemos entendido que el tiempo social está sostenido por la constitución del proceso de construcción del yo y del Nosotros. Hemos entendido, y así lo hemos fundamentado a lo largo de la investigación, que ambas realidades — la del Yo y la del Nosotros — no pueden entenderse de manera separada, es por ello por lo que hemos intentado responder a la cuestión: ¿Cómo se crea la interdependencia?

Hemos recordado el valor otorgado a la historicidad. Decimos esto porque este hecho marca y atraviesa todas las definiciones sociales creando un campo de análisis donde el tiempo no es que esté presente, sino que es el momento constitutivo. Así, detrás de la construcción del tiempo de lo social, se erigen los procesos de individualización colectiva, asociados a la interpenetración de la tradición en la modernidad o, incluso, de la modernidad hecha tradición. Este proceso aparece determinado por los indicadores estructurales que no son sino el producto del proceso que la modernidad pone en marcha. Nos hemos referido, bajo este epígrafe, a las transformaciones económicas que generan la aparición del industrialismo vasco y, con él, al significativo papel de la inmigración — auténtico hito estructural de la modernidad vasca-, el valor social del pluralismo como el indicador estructural y el descriptor de la modernidad vasca y con él rodeándole, y dándole sentido al pluralismo, el surgimiento de las realidades múltiples como aglutinantes sociales de la diversidad que acoge en su seno la sociedad vasca. Este entramado se forja a la vez 
que se produce el renacimiento del valor de la comunidad y de lo comunitario, de la estructura de comunicación que, cual soporte de una bóveda, tolera el despliegue comunitario y su materialización, no sólo en el nuevo rol de las relaciones interpersonales, sino también en el hogar, en la fábrica, en la ciudad, en el pueblo o en el barrio. La consecuencia es que los entramados societarios instrumentales coexisten con los entramados de la nombrada "comunidad vasca». Unos no niegan o rechazan a los otros, sino que ambos se refuerzan mutuamente, lo que provoca el surgimiento de nuevas formas de interdependencia.

El tiempo histórico transita desde el colapso del orden político de la tradición hasta la entronización del sueño de Europa. Entre uno y otro polo, entre uno y otro extremo, se asiste a la creación del moderno Estado nación, a las preguntas surgidas alrededor de la «evidencia» política del Estado nación y a la constitución de la lógica periférica frente a la lógica del centro. La excepcionalidad política se impone en muchos momentos en el marco del Estado español. Son las repetidas guerras civiles, son los golpes militares, es la travesía del franquismo y es la lógica de los vencedores y los vencidos la que impera en estos momentos. La creación de la democracia "inventa» un espacio novedoso donde pueden abordarse algunos de los déficits políticos e históricos y donde puede enunciarse la institucionalización de la heterogeneidad y la legitimidad de las diferencias, pero las dudas sobre el modelo no cesan, porque las tensiones sobre cómo organizar la vida societaria y las creencias comunitarias, cómo hacerlas compatibles, cómo superar la historia pasada o el dilema del papel de las instituciones en estos procesos, siguen sometidas a discusión sobre cómo gestionar la complejidad de la sociedad vasca o cómo crear cauces de encuentro entre el centro y la periferia. La mortífera existencia de ETA recuerda, con lúgubre persistencia, que los caminos de la paz y la normalización política no son todavía sino una promesa.

El tiempo político enlaza con el tiempo histórico y con el tiempo de lo social mediante los nexos de la memoria, del valor del recuerdo y de todo aquello que pudiera haberse hecho y dicho pero que o no fue posible o sigue pendiente. Entre estos sueños se encuentra, por ejemplo, lo que sea el estado o la imaginación abierta de la ilusión inconquistable del estado propio. La democracia se erige, en todos los casos, como el referente simbólico del tiempo fundante. La complejidad que atesora como nadie el orden de lo social, replantea la conexión y la desconexión entre nación y estado e incluso pone en evidencia como ambas realidades están sometidas a escrutinio permanente.

Los tres momentos reseñados conducen al cuarto que hemos analizado: la reflexión sobre el sentido de qué es la sociedad vasca. Expresado de otra manera, la capacidad de los agentes sociales para responder a las preguntas y con ellas generar respuestas sobre quienes somos nosotros. La reflexión sobre lo que es y sobre lo que representa la producción de la conciencia del Nosotros nos lleva a plantarnos ante el eterno dilema de la identidad.

$\mathrm{El}$ "conflicto de identidades» en la sociedad vasca no es sino el conflicto sobre la construcción del pluralismo, el conflicto de una realidad compleja, 
que es coherente desde la multiplicidad de ofertas identitarias que se abren ante el ciudadano.

Lo que nuestros entrevistados demuestran con sus respuestas, y lo que del análisis empírico hemos extraído, es que la conciencia de quienes somos nosotros está asociada a la idea del «somos porque estamos», lo cual quiere decir que las definiciones dependen de expectativas y están, en consecuencia, abiertas a múltiples influencias y a la oferta de propuestas y de soluciones entre las que cabe optar. Por eso, los ciudadanos delatan una actitud de consumidores, eligen entre la variedad de productos que encuentran en el mercado del sentido y clasifican estas ofertas dependiendo de la definición social que han hecho de ellas y de la importancia concedidas a unas y a otras. Nada se pasa por alto, unas y otras se encuentran ante los individuos que las clasifican, las dan un sentido y proclaman, con ellas, su identidad.

En el caso que hemos analizado, la conciencia del Nosotros penetra desde los mecanismos sociales creados en la vida cotidiana y sobre el humus estructural del imaginario que representa el «somos porque estamos». La consecuencia más importante es que la institucionalización de lo que representa la vida inmediata aparece como el universo que representa mejor que ningún otro los mínimos comunes con los que la sociedad vasca crea y busca su cohesión. Son, de esta manera, los vínculos sociales de la socialidad inmediata — pueblo, barrio, familia, amigos, trabajo, vivienda, etc. - los que generan la definición fuerte de la vivencia identitaria de quienes somos en la sociedad vasca. No ocurre lo mismo con todos aquellos signos que, siendo significativos, constituyen la representación de algunas de las realidades que coexisten en la sociedad vasca; sean, por citar dos ejemplos, la lengua o la política.

La presencia de una definición exclusiva sobre quienes somos Nosotros es inexistente en la sociedad vasca. Desde este punto de vista, sostenemos que no existe un centro que articule esta conciencia, sino que lo que afirmamos es que con lo que nos hemos encontrado ha sido con la existencia de múltiples periferias, algunas más prevalentes que otras, pero ninguna con la fuerza suficiente como para definir un terreno de juego "protegido" por el imaginario simbólico que cohesiona la diversidad de casi todo. Creemos que, por el contrario, la respuesta a la definición de ¿quiénes somos? se encuentra en la respuesta «porque estamos». Es decir, «somos porque estamos» diseña un cuadro factible de respuestas a los interrogantes y dilemas que hemos presentado a lo largo de la investigación. Es, precisamente, la seguridad que otorga la definición la que mantiene y reproduce la argamasa genérica de la cohesión.

La definición «estamos» se vehiculiza mediante las expectativas que provocan las instituciones que «atan», que «cosen» el mosaico de la presencia social. Los «cosidos» dependen de que las expectativas forjadas se cumplan, sean el bienestar personal o de la familia, las estrategias elaboradas para la prole, el trabajo, la educación, etc., pero todas asociadas a la significación que tiene la institucionalización de los mecanismos con los que cuenta la vida inmediata. Todas se presentan como instituciones activas que crean expectativas. Esto demuestra que el dilema de la cohesión no depende de llamadas extemporá- 
neas a vínculos imposibles, sino de la circularidad de las expectativas que se encuentran en el poder para institucionalizar las expectativas que tienen, además, el escenario de realización en los mecanismos y en las actividades de la vida inmediata.

De esta manera, las relaciones intergeneracionales aparecen como relaciones «tranquilas». Las generaciones se reconocen en el encuentro que provoca el contacto inmediato. Hay una cierta solidaridad y cercanía cuando se abordan objetivos y fines. Se entiende, se comprende y se sufre con los quebrantos de unos o de otros. La generación adulta encuentra, en la relación con la generación joven y con la estrategia hacia su prole, un elemento que, cuando tiene éxito, determina el cuadro de expectativas. Así es como la familia se "cuela" como el espacio protegido, el escenario social por excelencia que mantiene el imaginario de País cohesionado. La situación de la familia es el termómetro de cómo está funcionando socialmente la conciencia del Nosotros. Sería un error, a la luz de los datos aportados, separar la bondad de este entramado institucional inmediato de otras respuestas que aparecen en el catálogo de las diferentes periferias. Son estas respuestas de la vida inmediata las que atraviesan, son la representación de la transversalidad, el eje y el centro de la argamasa sobre la que se erige la conciencia del Nosotros. Diríamos más, sin los cimientos «inmediatos" sobre los que se erige esa argamasa no es posible pensar noción alguna del Nosotros.

Lo que esto nos está indicando es que el edificio de lo social no se sostiene desde la afirmación de los particularismos identitarios, sino desde la definición de las expectativas que unos y otros están dispuestos a perseguir desde la institucionalización de las instituciones que componen la vida inmediata. Aquellos aspectos que generan disrupciones son apartados, separados de la clasificación jerárquica de todo aquello que produce sentido. Ocurre esto, por ejemplo, con la política. Aunque, paradójicamente, casi todo el mundo declara estar interesado por ella, se erige una especie de velo, de frontera simbólica que cubre sus expectativas y su contemplación. Se es consciente, y así se dice, que separa o qué de poco sirve debido al manejo que de ella hacen los políticos o, en algunos casos, el miedo, el temor a lo que «me puede pasar» se filtra entre las opiniones de nuestros entrevistados.

Parece establecido que el filtro de la política no cohesiona, sino que divide, y como la cohesión y la «buena vida» son más importantes que la pasión política, esta segunda se deja de lado. Diríamos que la política, para muchos ciudadanos, es un problema y lo que buscan es protegerse de la fuente que provoca la insatisfacción. No diríamos, por otra parte, que la política carece de interés para los ciudadanos entrevistados. Todo lo contrario. La política es una pasión y como tal se vive. Pero la paradoja que genera es que el interés por ella se mueve prácticamente en el terreno de lo privado. Es como si los que formulan su relación con la política lo hicieran a sabiendas de que su "pasión» deberá permanecer en la esfera de lo privado, porque, si se hace público, genera "problemas», discusión, debate, etc. De esta manera, es como la política se transforma en fuente de fricciones, es necesaria para «jugar» en el espacio de los cosidos 
sociales, pero "su» necesidad se vuelve en contra de su funcionalidad. Esto no quiere decir que no sea un elemento significativo. Lo es. Pero lo es desde la defensa particular que cada cual hace de su definición. Es así como la política y lo político cobrará valor no como elemento generalizable, sino como elemento definido desde su espacio concreto, desde el universo simbólico particular de cada una de las periferias más sobresalientes. No deja de ser esta forma de abordar aquello que impide la cohesión un mecanismo de defensa que permite aportar, al menos relativamente, «lo que rompe», es decir, los elementos disruptivos que podrían ocasionar «potencialmente» daños a la estructura de gratificaciones, a la conciencia del Nosotros.

Lo significativo es que se genera una red de mecanismos explícitos e implícitos empeñados en mantener algo evidente, «somos porque estamos», no «somos» porque tengamos una lengua común o una misma definición sobre cuál es la política correcta o la mejor identidad política, sino que lo que "ata» es el hecho consciente de compartir expectativas, de poseer algunos bienes que se expresan, sobre todo, en la vida inmediata. En algunos casos, pueden ser importantes las definiciones fuertes, pero realmente no es «lo fuerte» lo que mantiene unida la estructura simbólica de la conciencia del Nosotros, esos elementos pueden ser y, en ocasiones, son muy importantes para un sector social, pero no lo es de igual manera para otro. No olvidemos que los mecanismos débiles adquieren la máxima fortaleza en su debilidad.

Es relevante que la conciencia del Nosotros se despolitiza, se privatiza. A la vista de los datos, la conclusión es que ha encontrado la fortaleza y la significación de su fuerza en la institucionalización de las instituciones del curso de la vida. Éstas son el soporte y el lado fuerte de su identidad.

Progresivamente, la definición «Nosotros» se asocia a la definición «estamos». Se ha desdiferenciado y se ha encontrado con la imposibilidad de recurrir a mecanismos «incuestionados» hasta hace poco tiempo; lengua y definición política de la identidad. Ambos han perdido peso específico en la definición de la conciencia del Nosotros, por más que la sigan conservando entre aquellos segmentos de la sociedad, entre aquellas periferias para las que esos elementos siguen siendo importantes. Podría decirse que, para la definición social del «estamos», los ingredientes particulares de cada segmento social son significativos porque se elevan sobre aquello que los hace posibles. La lengua, la política, la identidad política, etc., son porque la institucionalización de las expectativas que se vehiculizan en la vida inmediata los hacen posibles. Por eso, ni las discusiones públicas, ni los discursos alrededor del «qué somos» tienen excesivo sentido en cuanto son unos términos y unas respuestas que ya están clarificadas. La "clarificación» no depende de esencia alguna a descubrir o a inventar, sino del funcionamiento de los mecanismos y de las instituciones de la vida cotidiana. Ellas generan y ellas mantienen las expectativas seguritarias.

En nuestro estudio, la idea compartida de seguridad se muestra a través de la experiencia colectiva de que «somos porque estamos». Autopresentación de la concepción sociopolítica que tiene de sí misma la sociedad vasca donde se concita tanto lo sincrónico (el ser/estar) como lo diacrónico (el devenir o llegar a 
ser/estar) y, asimismo, se hace reconocible el proceso de conformación de un marco común de seguridad: proceso en el que las instituciones re-crean expectativas, las generan y las renuevan; expectativas que, institucionalizadas, se constituyen a su vez en el horizonte de sentido de dichas instituciones, mostrándose así no sólo como meros productos, sino también como productoras de éstas. Proceso en el que no cabe reducir las unas a las otras o las otras a las unas, pues lo que en el mismo se dirime, una y otra vez, es el doble movimiento por el que ambas se presuponen y se in-determinan activamente:

$$
\text { Instituciones } \rightleftarrows \text { Expectativas }
$$

En este sentido, la imagen de que «somos porque estamos» supone una representación u objetivación narrativa de la serie de expectativas institucionalizadas que aquí y ahora nos constituyen en un «nosotros». De ahí que, al tomar en consideración dicha imagen, no hagamos otra cosa que plantear la seguridad en los términos de un imaginario colectivo o, si se prefiere, en el conjunto de formas específicas y modos legítimos del «hacer visible» de una sociedad y en una época concretas. De hecho, la imagen de que «somos porque estamos» no sólo nos da a ver la idea común de seguridad en la sociedad vasca de comienzos del siglo XXI, sino que, además, nos la hace ver de una determinada manera, aquélla que le es tanto propia como apropiada a esta sociedad en este momento de su historia social. Presente caracterizado por lo que supone mantener o atenerse a lo que nos «une» $\mathrm{y}$ "ata» (somos...), tanto como por no desdeñar sino atender a lo que comporta su configuración (...porque estamos). 